\title{
Microstructure and wear behavior of friction stir processed cast hypereutectic aluminum silicon
}

\author{
Rosli Ahmad ${ }^{1}$, Samir Sani Abdulmalik ${ }^{1, *}$, Ojonimi Yusuf Usman ${ }^{1}$, and Sufyanu Bashir \\ Danjuma $^{1}$ \\ ${ }^{1}$ Department of Manufacturing and Industrial Engineering, Faculty of Mechanical and Manufacturing \\ Engineering, Universiti Tun Hussein Onn Malaysia, 86400 Parit Raja, Batu Pahat, Johor, Malaysia
}

\begin{abstract}
Hypereutectic as-cast $\mathrm{Al}-18 \mathrm{Si}-\mathrm{Cu}-\mathrm{Ni}$ alloy was subjected to friction stir processing (FSP). The resultant effect of FSP on the alloy was evaluated by microstructure analysis and wear tests (dry sliding). A significant microstructural modification and enhancement in wear behavior of $\mathrm{Al}-18 \mathrm{Si}-\mathrm{Cu}-\mathrm{Ni}$ alloy was recorded after friction stir processing. Wear resistance improvement was related to considerable modification in size, morphology and distribution of silicon particles, and hardness improvement. It was found that lower tool rotation speed was more effective to refine silicon particles and in turn increase wear resistance. Minimum Si particle mean area of about $47.8 \mu \mathrm{m}^{2}$, and wear rate of 0.0155 $\mathrm{mg} / \mathrm{m}$ was achieved.
\end{abstract}

\section{Introduction}

Al-Si alloys are among the materials of tribological relevance, and continued to receive considerable attention due to their good castability and machining characteristics [1]. Past studies [2, 3] reported that Si particle morphology, size, and content, significantly affects the wear resistance of these alloys. The size and morphology of the Si particles are considered to be factors controlling the formation and propagation of cracks [4]. Alidokht et al. [2] reported that under dry sliding conditions the tendency toward cracking for larger $\mathrm{Si}$ particles is greater. It was noticed in [3] that the refinement of Si particles in Al-Si alloys increased the wear resistance. Silicon particles having even and rounded morphology can delay crack nucleation and growth processes in the subsurface region [2].

Hypereutectic Al-Si-Cu-Ni alloy is among the widely used commercial aluminium silicon alloys in automotive industries for piston application. However, coarse eutectic Si structure, segregation of the primary $\mathrm{Si}$ particles, and porosity affects the mechanical properties of Al-Si-Cu-Ni alloy particularly, fatigue, and wear resistance [5]. In order to solve these problems, a practical technique of microstructure modification which can effectively reduce the porosity and uniformly redistribute the fine $\mathrm{Si}$ particles in the aluminum matrix is imperative. Recently, friction stir processing (FSP), a variant of friction stir welding (FSW), in which the intense plastic deformation generated by traversing a welding tool [6] has been used as a technique to locally modify the microstructure in a

\footnotetext{
* Corresponding author: samiralhaji@yahoo.co.uk
} 
number of Al-Si cast alloys [7-9]. In FSP a rotating tool with a designed pin and shoulder is plunged into a monolithic workpiece and produces a recrystallized fine particles microstructure within the stirred zone (SZ). Detail explanation of the process if given elsewhere [10]. Previous investigation [11] shows that FSP significantly refined the microstructure of cast $\mathrm{Al}-\mathrm{Si}-\mathrm{Cu}-\mathrm{Ni}$ and created a uniform distribution of fine $\mathrm{Si}$ particles in the matrix, which is known to be very effective in enhancing wear resistance [2]. Thus, it is important to evaluate the wear behavior of FSPed Al-Si-Cu-Ni. In the present work, the evolution of microstructure during FSP at two different tool rotational speeds and its effects on wear resistance and hardness of Al-Si-Cu-Ni alloy was investigated.

\section{Experimental procedures}

In this study, hypereutectic Al-Si alloy with composition: $18 \mathrm{Si}, 0.9 \mathrm{Cu}, 1.15 \mathrm{Ni}, 0.2 \mathrm{Mn}$, $0.16 \mathrm{Mg}, 0.06 \mathrm{Zn}, 0.19 \mathrm{Fe}$, and $80.34 \mathrm{Al}$ (wt.\%) was subjected to single pass FSP in longitudinal direction. The as received ingots are machined into plates having $30 \mathrm{~mm} \times 150$ $\mathrm{mm} \times 7 \mathrm{~mm}$ dimensions. A non consumable cylindrical profile tool made from $\mathrm{H} 13$ steel was used to carry out the FSP. The tool has a shoulder diameter of $17 \mathrm{~mm}$, pin diameter $6 \mathrm{~mm}$, and pin length $3.5 \mathrm{~mm}$. The FSP experiment was performed using vertical milling machine at a fixed transverse speed of $42 \mathrm{~mm} / \mathrm{min}$, and tool rotating speeds: $1000 \mathrm{rpm}$, and $1400 \mathrm{rpm}$. For all the experiments, tool tilt angle was set to $3^{\circ}$, and tool down force was kept constant. The FSP setup is illustrated in Fig.

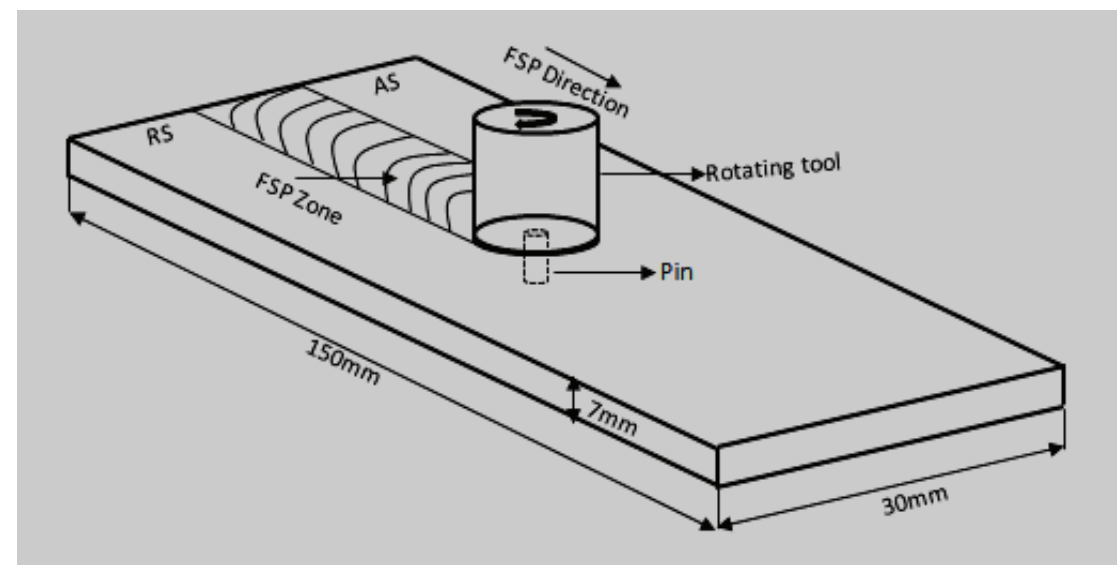

Fig. 1: Illustration of FSP setup

Microstructural evaluation was performed on the samples cross sections after FSP. Samples were ground using different grades of sand paper up to 1200 grit, polished with alumina paste, then etched in hydrofluoric acid $0.5 \mathrm{M}$ solution to reveal the microstructures. The samples microstructure examination was accomplished using optical microscope. Image analysis technique was used for determining the sizes of the silicon particles, and there aspect ratio. Microhardness is measured across the FSP samples transverse crosssection, using a load of $500 \mathrm{~g}$ for $10 \mathrm{~s}$.

Fig. 2 shows the schematic illustration of the wear test experiment, the tests were conducted on a pin-on-disk tribometer. Rectangular specimens (pin) of $4 \mathrm{~mm} \times 3 \mathrm{~mm}$ dimension were carefully cut from the surface of FSPed samples, with their axis perpendicular to the tool travel direction. To have a uniform surface wear samples were ground using 1200 grit sand paper and polished with alumina solution, cleaned with 
acetone and dry before the test. The tests were performed against a counterpart stainless steel disc. Before each test the disc was polished on 1200 sand papers. The sliding speed and the normal load were fixed at $0.5 \mathrm{~m} / \mathrm{s}$ and $20 \mathrm{~N}$, and the sliding distances were varied up to $1000 \mathrm{~m}$. At certain intervals wear tests were halted to determine the progress of wear. Each time, samples were cleaned in acetone and weighed to an accuracy of $\pm 0.1 \mathrm{mg}$. Rates of wear were measured as the ratio of mass loss to sliding distance, then examined the wear samples worn surfaces using scanning electron microscope (SEM).

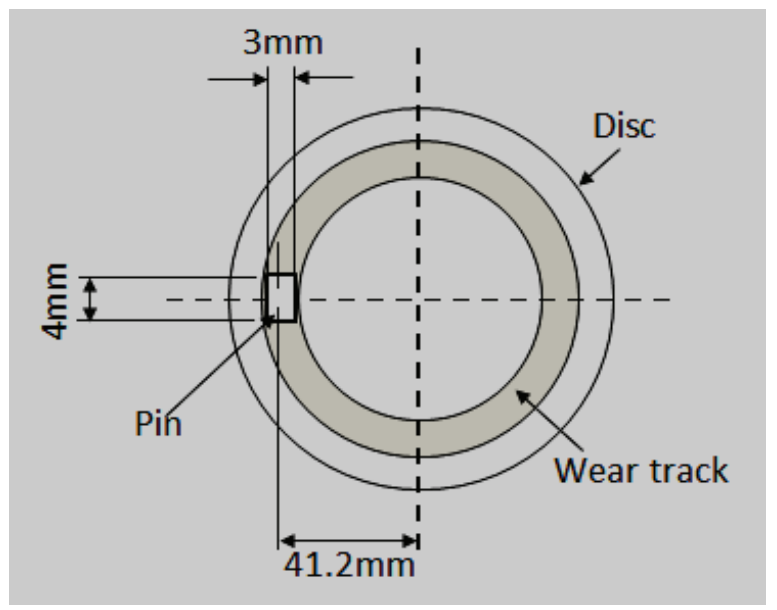

Fig. 2: Configuration of the pin-on-disc wear test; run for $1000 \mathrm{~m}$ sliding distance

\section{Results and Discussion}

Fig. 3 shows a micrograph of the as cast hypereutectic Al-18Si-Cu-Ni alloy. The base alloy consists of coarse primary silicon, and needle-like/platelet eutectic silicon morphology. The dispersal of the silicon particles was not uniform all through the aluminium matrix. Measured mean area of the eutectic and primary $\mathrm{Si}$, was about $155.1 \mu \mathrm{m}^{2}$ with aspect ratio of 2.86 .

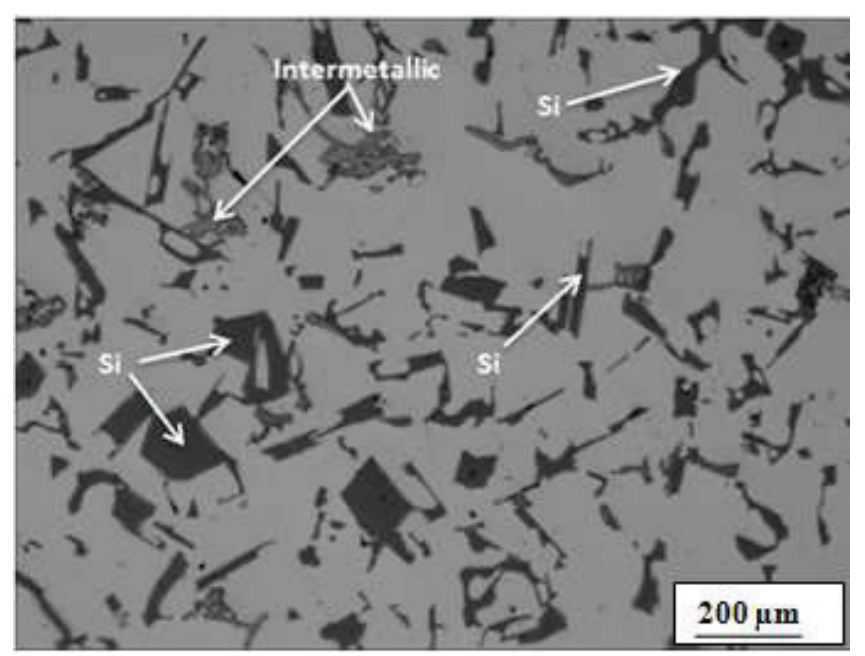

Fig. 3: Microstructure image of Al-18Si-Cu-Ni base alloys 
Fig. 4(a-b) shows the optical micrograph at the center of the stir zone SZ of FSPed Al-18Si$\mathrm{Cu}-\mathrm{Ni}$ samples at various rotation speeds. It is clear that the stirring action of the tool during FSP brings about a significant breakdown of the coarser Si particles and creates a better dispersion of finer Si particles in the stir zone. This is related to thermal exposure and plastic deformation with a strain rate of 100 to $1000 \mathrm{~s}^{-1}$ and strains up to -40 during FSP [2]. The variation of silicon particles of FSPed, and as cast Al-18Si-Cu-Ni samples are presented in Fig. 5. In the whole stir zone SZ of FSPed Al-18Si-Cu-Ni samples, regardless of the tool rotation speed the silicon particles area size and aspect ratio decreases as compared to the as cast base alloy, as a result of the intense stirring effect. Such microstructure transformation is been reported in other Al-Si alloy [6]. However, raising the tool rotation speed above $1000 \mathrm{rpm}$ does not cause further significant refinement of the silicon particle, which means, the mean area size of the silicon particles increases with increased heat input [9]. This is related with the enhanced flow-ability of the matrix as a result of high localized heat input conditions at higher tool rotational speeds, that soften the material around the tool pin and caused the Si particles flow with the plastic flow of the matrix $[2,8]$, and therefore the breakdown of the silicon particles would not intensified further [2]. In this study tool rotation speed of $1000 \mathrm{rpm}$ gives the minimum mean area size and aspect ratio of $47.8 \mu \mathrm{m}^{2}, 1.69$ respectively.
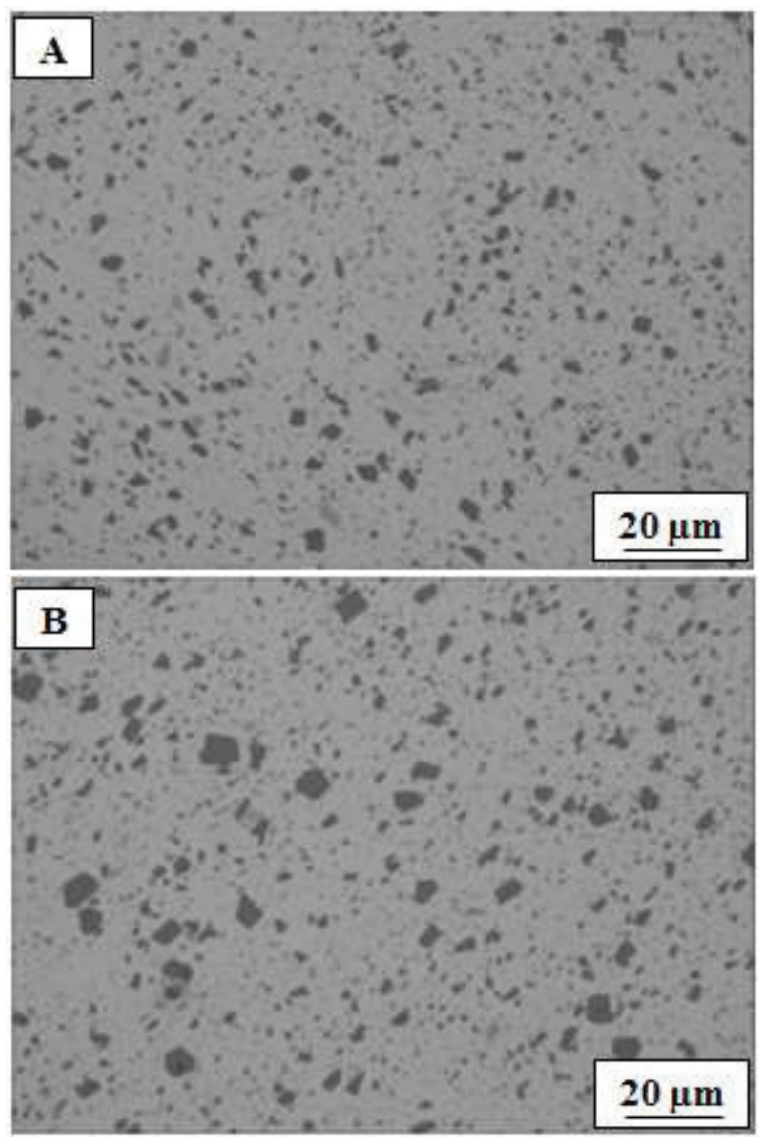

Fig. 4: Optical micrograph from the center of stirred zone of FSPed Al-18Si-Cu-Ni alloy at (a) 1000 rpm, and (b) $1400 \mathrm{rpm}$ 


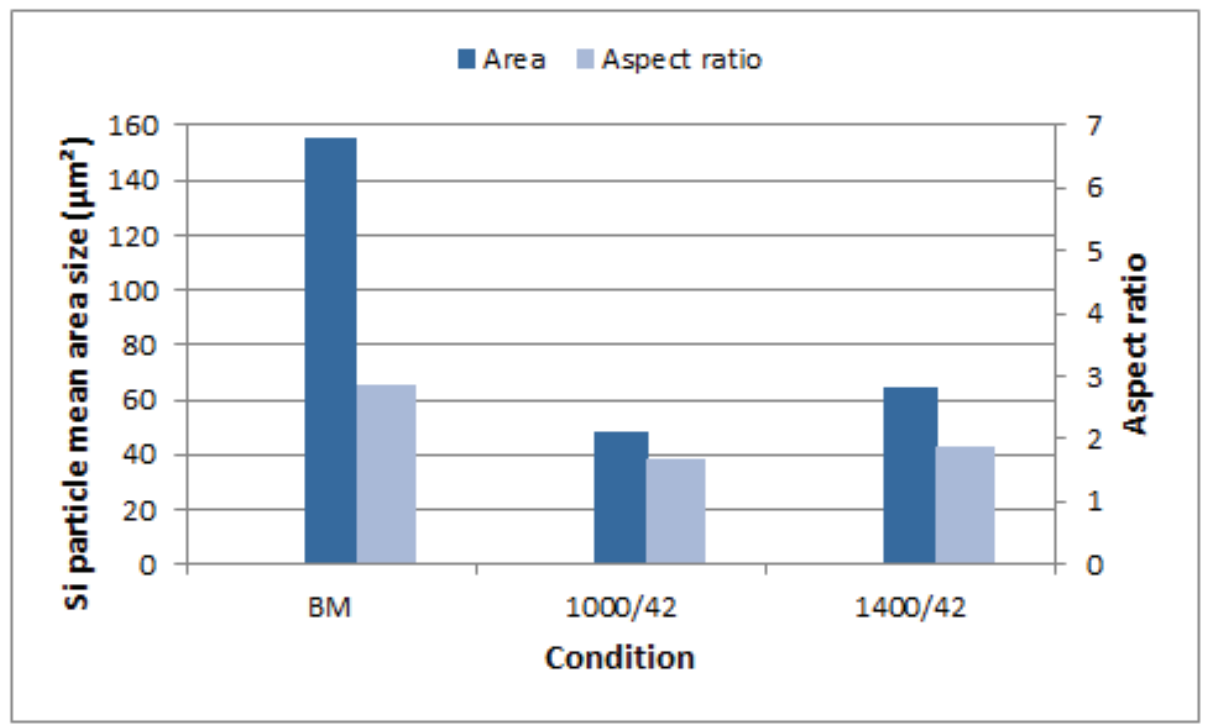

Fig. 5: Si particles mean area sizes, and aspect ratio of base alloy and FSPed Al-18Si-Cu-Ni samples, at various tool rotational speeds

Fig. 6 shows the microhardness values of the samples before and after FSP at various rotation speeds. The hardness enhancement within the SZ is considered due to fine dispersion of silicon particles in the aluminium matrix Fig. 3, and eliminating the as-cast defects [2, 12]. Alidokht et al., [2] reported the refinement in microstructure of friction stir processed cast Al-Si alloys. They observed that, hardness improved in the stir zone as a result of the modification, fragmenting and homogenization of the Si needles in the eutectic phase.

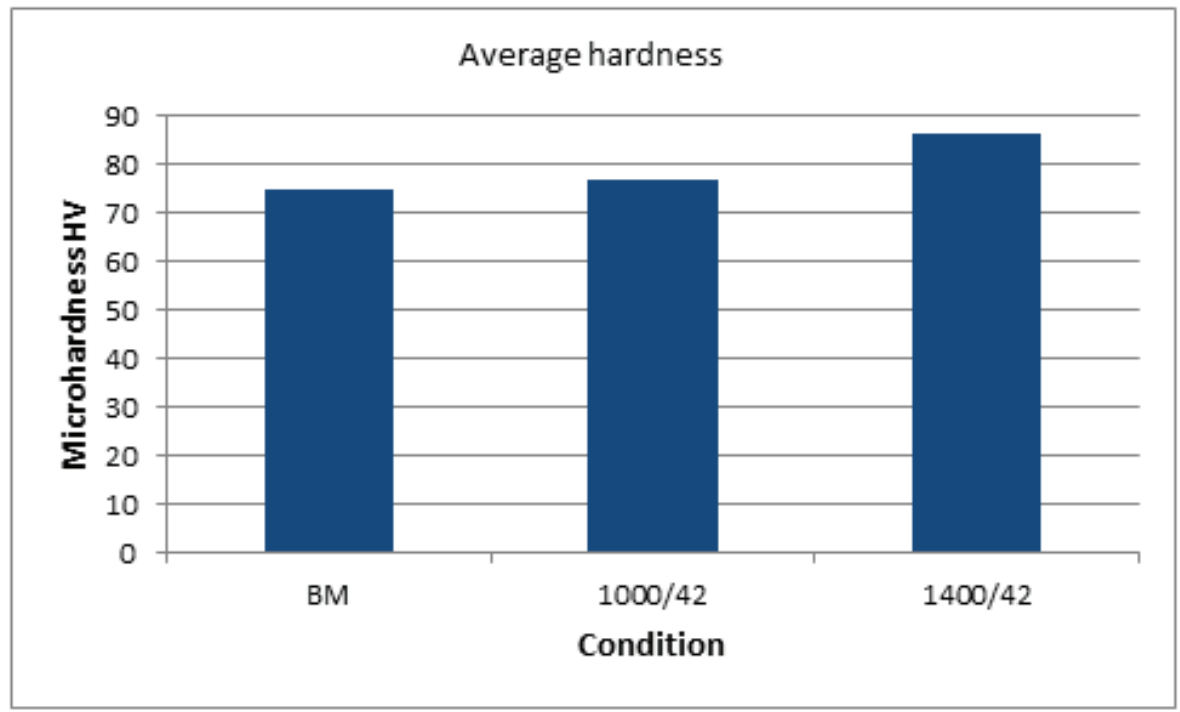

Fig. 6: variation of hardness 
The relationship between sliding distance and the mass loss of as cast and FSPed Al18Si-Cu-Ni samples is presented in Fig. 7. It is obvious the wear mass loss increases with sliding distance. Also from the figure, the extent of wear is considerably less in FSPed samples compared to the as-cast $\mathrm{Al}-18 \mathrm{Si}-\mathrm{Cu}-\mathrm{Ni}$. Fig. 8 shows the graph of wear rate (obtained from; wear mass loss/sliding distance). At the initial stage of wear (sliding distance), the rate of wear for FSPed samples appear high, and decreases thereafter as the sliding distance increase. Whereas the mass loss curves of the FSPed samples is somewhat steady state at higher distances. For the as cast Al-18Si-Cu-Ni sample, it curve appeared increasing with a constant rate. It can be inferred from the results that after performing FSP the wear resistance of as-cast $\mathrm{Al}-18 \mathrm{Si}-\mathrm{Cu}-\mathrm{Ni}$ alloy significantly improved.

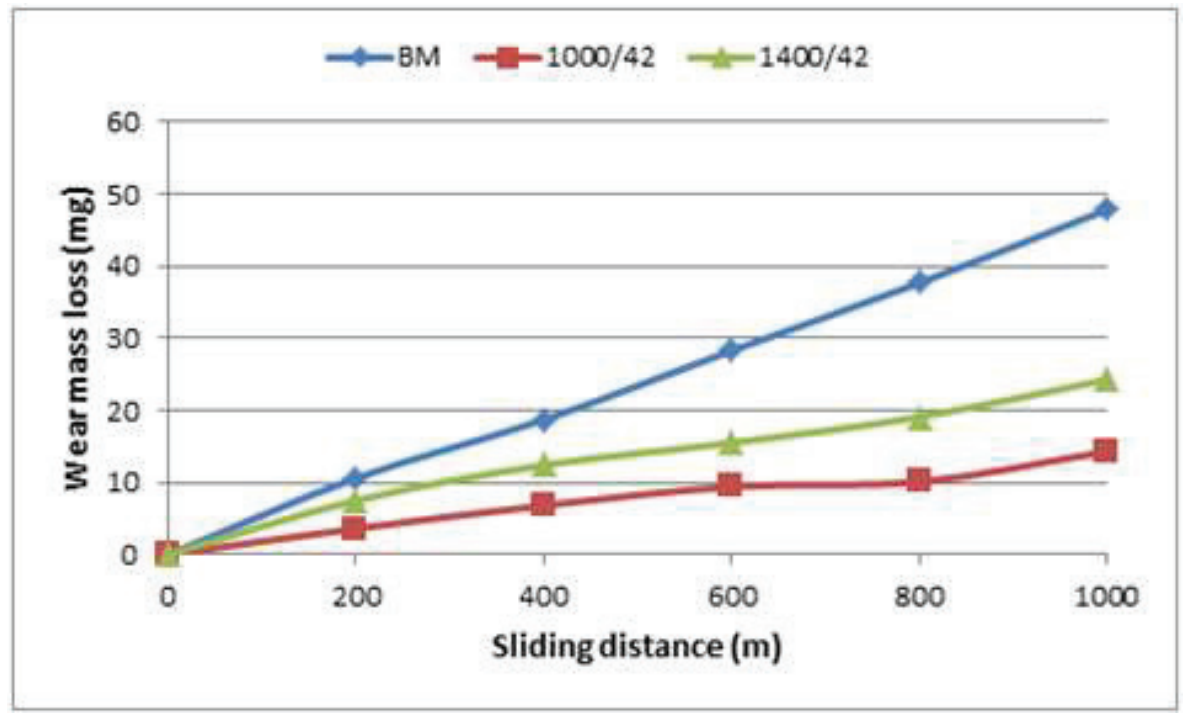

Fig. 7: Graph of wear mass loss

The sample processed at $1000 \mathrm{rpm}$ tool rotation speed display slightly higher resistance to wear compared with the samples processed at $1400 \mathrm{rpm}$ rotation speed. This result is similar to the one reported by Mahmoud and Mohamed [9], on FSP A143 Al-Si alloy.

SEM micrograph of Al-18Si-Cu-Ni cast alloy worn surface after $1000 \mathrm{~m}$ of dry sliding at linear velocity of $0.5 \mathrm{~m} / \mathrm{s}$, and force $20 \mathrm{~N}$ is shown in Fig 9a. Severe damage and long grooves can be seen on the worn surface. That deep craters and cracks on the worn surface show that delamination have taken place. This mean, on the side facing sliding direction, plastic deformation layer fractured to form small lumps and then delaminated [5]. Fig. 9 (bc) presents SEM images of the FSPed worn surfaces. As can be seen the FSPed surface is less damaged compare with that of the as-cast sample. Wear mechanisms: both abrasion and delamination were observed in all the FSPed samples. It can be seen from Fig. 9 (b-c) that the deep grooves on the surface of both FSPed samples are less. This supports the lower wear rates of FSPed samples compared to that of the as-cast samples Fig. 8. The observed enhancement in wear results may be related to the enhancement of the alloy hardness as a result of microstructure refinement Fig. 4. Under abrasive wear condition, it is well known that the wear resistance of the material decreases with increasing hardness $[2$, 13]. Additionally the morphology, size and distribution of silicon particles in the FSPed Al$18 \mathrm{Si}-\mathrm{Cu}-\mathrm{Ni}$ samples contributed to the wear resistance. 


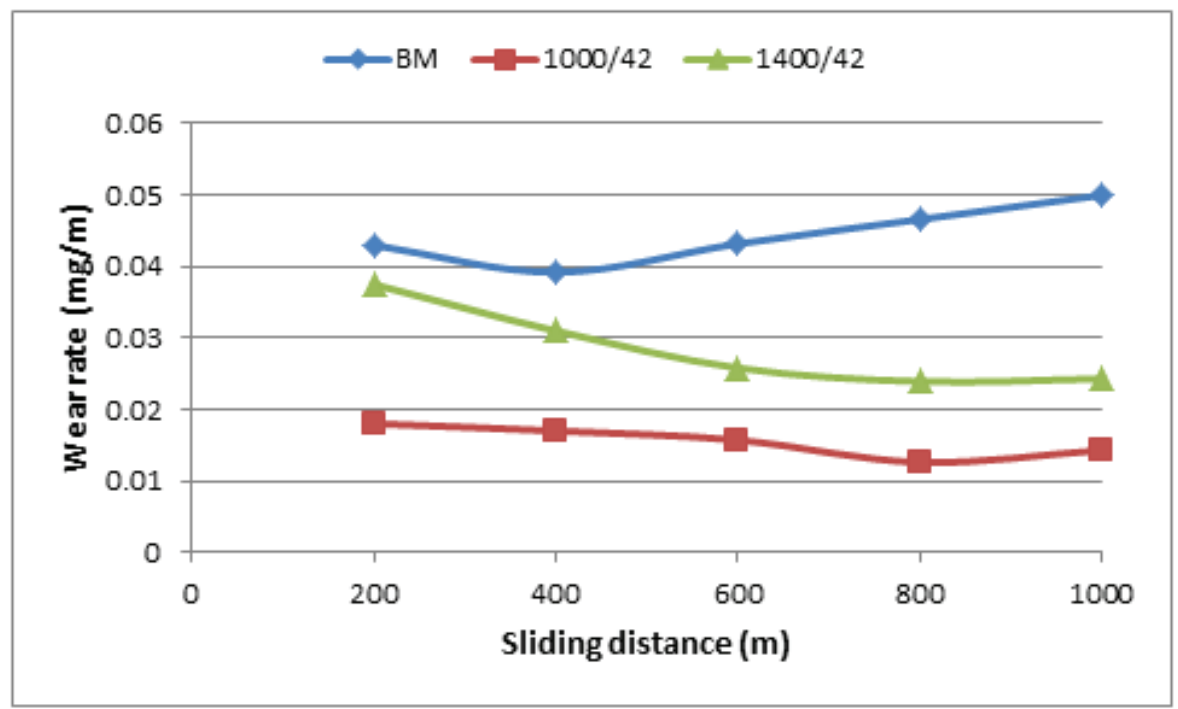

Fig. 8: Graph of wear rate

It is well known that larger, coarse irregularly shaped Si particles with large aspect ratio present in a material may lead to stress concentrations at the silicon matrix interface, and facilitates path for propagation of cracks [2].
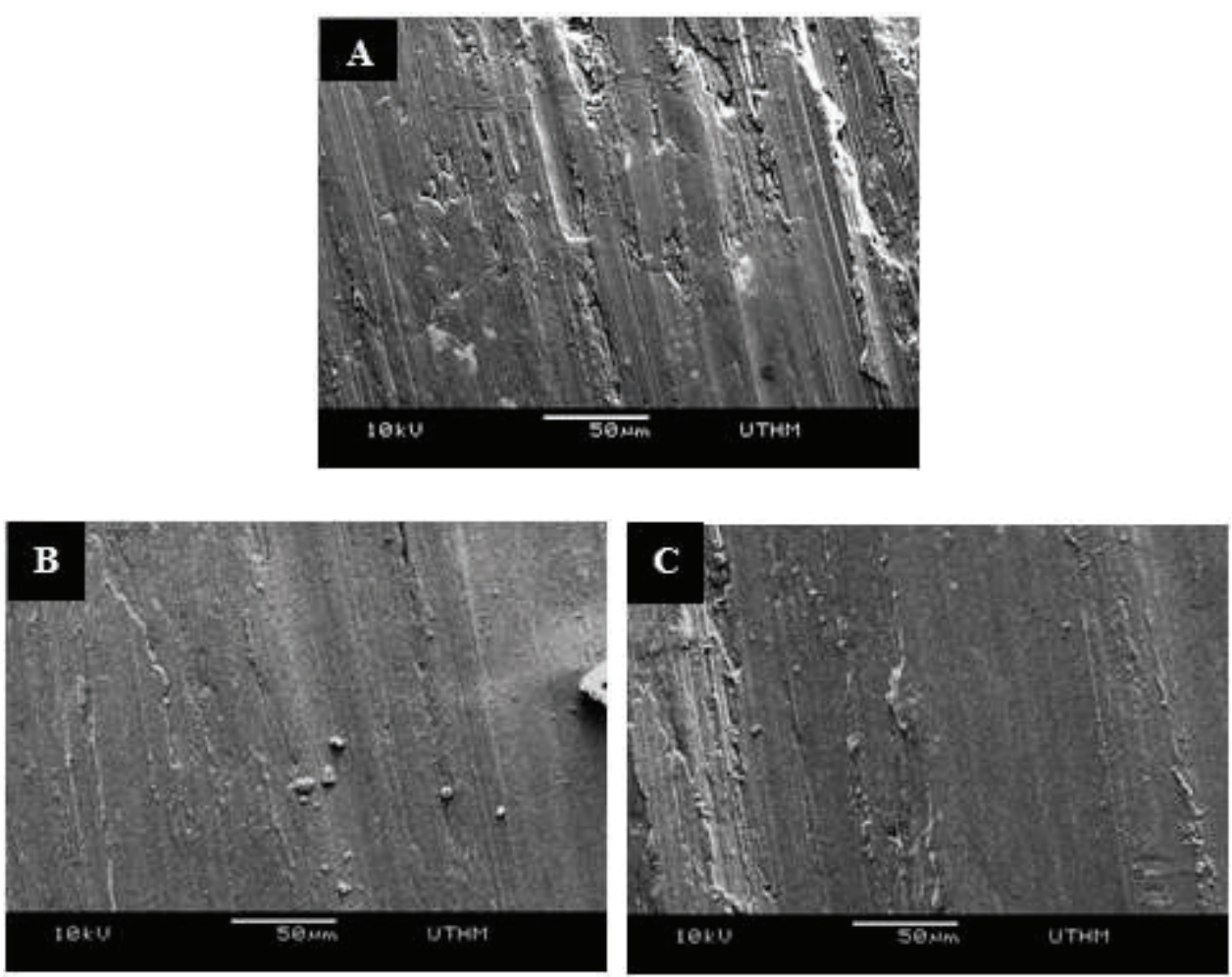

Fig. 9: SEM micrographs of the sample worn surfaces (a) as cast based metal, (b) as FSPed at 1000 rpm, (c) FSPed at $1400 \mathrm{rpm}$ 


\section{Conclusions}

In this study, cast hypereutectic Al-18Si-Cu-Ni alloy was subjected to FSP under different rotational speeds, and it microstructure, hardness and wear properties were investigated. FSP results in a significant breakup of large coarser eutectic and primary silicon particles, and subsequent uniform distribution of smaller Si particles throughout the Al-18Si-Cu-Ni matrix was achieved after FSP. Increasing tool rotation speed causes increase in Si mean area size, due to increased thermal exposure. At $1000 \mathrm{rpm}$ tool rotation speed, mean area size and aspect ratio of the Si particles were measured as: $47.8 \mu \mathrm{m}^{2}$, and 1.69 respectively, compared to the $155 \mu^{2}, 2.86$ in as-cast Al-18Si-Cu-Ni. The FSPed samples exhibits higher hardness value compared to the as-cast base alloy. This is related to the considerable microstructure refinement, and homogenization. Resistance to wear in the FSPed samples was observed to be better than that of the cast Al-18Si-Cu-Ni. This improvement is related to increased value of hardness and a better dispersion of finer, near circular silicon particles. At lower tool rotational speed the difference in wear rate is more pronounced.

\section{References}

1. V.C. Srivastava, R.K. Mandal, S.N. Ojha, Materials Science and Engineering A, 304, 555-558 (2001)

2. S.A. Alidokht, A. Abdollah-zadeh, S. Soleymani, T. Saeid, H. Assadi, Materials Characterization, 63, 90-97 (2012)

3. M. Elmadagli, T. Perry, A. Alpas, Wear, 262, 79-92 (2010)

4. H. Lashgari, S. Zangeneh, H, Shahmir, M. Saghafi, M. Emamy, Materials \& Design, 31, 4414-22 (2010)

5. T. Mahmoud, Surface and Coatings Technology, 228, 209-20 (2013)

6. S.S. Abdulmalik, R. Ahmad, M.B. Asmael, In AIP Conference Proceedings, 1831, 020037 (2017)

7. Z. Ma, A. Pilchak, M. Juhas, J. Williams, Scripta Materialia, 58, 361-6 (2008)

8. Z. Ma, S. Sharma, R. Mishra, Metallurgical and Materials Transactions A, 37, 11 (2006)

9. T. Mahmoud, S. Mohamed, Materials Science and Engineering A, 558, 502-9 (2012)

10. R.S. Mishra, P.S. De, N. Kumar, Springer, 13-58 (2014)

11. F. Tsai, P. Kao, Materials Letters, 80, 40-2 (2012)

12. N, Saini, D. Dwivedi, P. Jain, H. Singh, Procedia Engineering, 100, 1522-31 (2015)

13. Y. Chen, K. Nakata, Materials characterization, 60, 12 1471-5 (2009) 